\title{
Len D'Cruz: 'Have we been short changing patients for the last 20 years?'
}

Please send any ideas for feature articles for consideration to:

Ruth Doherty,

Managing Editor,

British Dental Journal

The Macmillan Building,

4-6 Crinan Street,

London,

N1 9XW

Email: r.doherty@nature.com

Len D'Cruz talks to the BDJ about change management, NHS England pilots and direct access for DCPs.

\section{Why did you choose dentistry?}

It certainly wasn't a burning ambition as a kid. I suppose I wanted a profession and a job that gave me a sense of pride. So it was very much the security and prestige that drove me to dentistry. I was torn between studying English and dentistry at university. My English teacher pointed out that it is possible to do English in your spare time by reading books etc but you can't do dentistry part time. That was good advice.

Because it's not a subject you specifically study at school the difficulty is that you don't know what dentistry really is until you get to university. Only later on, after being in practice for a couple of years, do you truly realise what it is all about. You understand then the significance of actually caring for people and the professionalism required. As an undergraduate it seems very academic.

\section{In what way has running a large multi-surgery practice changed over the past 20 years?}

I think it has become more bureaucratic. There are also more patient demands and we have had to become more patientfocused as a result. It is about the patient more than it is about you, the dentist, now more than ever before.

The issue about staff and employment law is always there - I don't think that has gotten any worse. The harder bit of dentistry now is the paperwork (CQC, compliance etc) to the point that we now

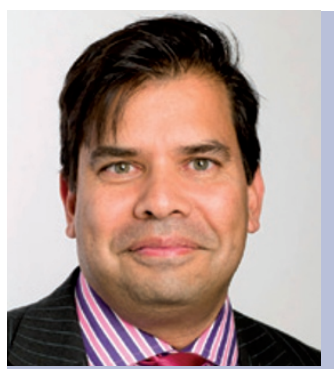

Len D'Cruz graduated from the Royal London Hospital in 1989. After completing his vocational training in Hertfordshire he bought Woodford Dental Care with his wife in 1992 and developed it from a one-surgery practice to a busy five-surgery practice. In addition to his own general practice work, Len is also a dento-legal advisor for Dental Protection Ltd. He obtained a Masters in Law from Cardiff in 2003. He has written a book, Legal aspects of general dental practice and has co-authored a popular guide to the NHS dental contract, Understanding NHS dentistry.

Len is also a Dental Practice Adviser for NHS England and a postgraduate dental tutor in the Eastern Deanery. He was appointed as the youngest examiner for the Royal College of Surgeons postgraduate dental exam and is currently an examiner for the MJDF (Membership of the Joint Dental of the Royal College of Surgeons of England). He is currently a member of the BDA General Dental Practitioners Committee.

have a practice manager. When I started the practice in 1992 we had one health and safety folder that pretty well covered everything but you need at least 20 folders now! I think that because of this single-handed practices are really going to suffer.

\section{Where has the patient-focused emphasis come from?}

From the patients themselves. I also think it's driven partly by the profession and the media. Patients are more aware of their rights and the choices that are available. If they are not getting those choices they will either demand them or walk. Patients now have a voice whereas 20 years ago they would've gone along with whatever the dentist suggested. Now before they even walk through the door they have looked on the internet and read Trip Advisor type reviews on NHS Choices as well as your own website and know a little bit more about your practice.

\section{Your practice is part of the new NHS contract pilots - what is your experience of this?}

We are part of a type I pilot and it's going very well. Though it has been a complete sea change. It has completely transformed the way we've thought about the practice and the way we deliver care.

My strong view is that we may well have been short-changing patients for the last 20 years by being paid in a certain way to deliver a certain thing. We are basically dealing with two largely preventable diseases - gum disease and tooth decay - and we haven't actually prevented them. If this contract becomes the first time that we are able to deliver that care ethically and in a way that is financially viable, then it will provide a fantastic opportunity. I think the future is going to have to be based on capitation and the care pathway, not on activity. The care pathway is in its infancy to a certain extent but it will deliver 
predictable care. I'm very excited to be part of it. My only fear is how it translates when the pilots are over. Someone from the Treasury or Department of Health could tinker with it. In its purest form it works tremendously well and it has a great future. It will come down to the fine detail in the end.

There is a risk of deskilling but that is where team work will work. It will be team members who benefit from this and possibly dentists won't. I think that the cohort of clinicians actually doing interventive work will be fewer and fewer, and more people will be doing preventive dentistry. There will still be a need to do highly skilled treatments for a population that will retain their teeth for longer but not to the extent we currently have. As a profession we would have to rethink how we deliver care and educate our dentists, and about our workforce numbers. Even if we looked at the workforce now it would be seven to eight years before those changes would be seen. We are actually doing the profession a disservice by waiting to see what will happen. The members of the profession won't necessarily be beneficiaries in the short- to medium-term though perhaps in the future, yes. The real beneficiaries will be the patients.

\section{How did your staff deal with the changes involved in the pilot?}

It was very difficult, particularly because we had no real training to do it. The biggest impact on the practice was an increase in our waiting times. The basic building block of the new system is the oral health assessment, which takes time. Instantly we went from 15 minute checkups to 30 minute check-ups, thereby doubling the waiting time. So this was a huge effect. Of course, this meant that the reception was like a battle zone. Staff had to fend off patients asking about increased waiting times. The associates were resisting it as they heard that our patients were changing to other practices and they were being paid in a different way. You start to doubt why you are doing it because you are risking your own business and livelihood.

The practice team is now on board and they understand why we are doing it. They realised that the existing NHS contract was not providing as good a service as it should. The initial impact of increased waiting times on the patients is what made the staff resist it. I think our staff are now committed because they understand the fundamental basics of it. Also we have changed the appointment system and reconsidered our pay structure. Associates are now paid on a sessional basis rather than by activity. So it has been a huge change but the practice team has been fantastic. They have supported the concept and we have come through it quite well.

The biggest 'management change' was to reorganise the appointment books (zone them) so you actually had specific oral health assessment, pain patient and treatment slots. One of the initial concerns was that patients came in to have their oral health assessments and then had to wait 6-8 weeks for their treatment. It helps if you have a zoning system to ensure that the time is used in a productive way. Once that system is in place and you stick to the rules, it works. For example, if a patient cancels an oral health assessment appointment you can't fill that slot with a treatment patient. It's taken some effort to work it but the team now know why we are involved.

\section{What is involved in being a dental practice advisor?}

I became a dental practice advisor in 2005 for the local PCT in North East London. At the time, the career pathway kind of said that you became an associate, then a practice owner, then a dental practice advisor. The role at that time was as the intermediate between the PCT and dentist, the "friendly face of the PCT'. You did practice inspections, acted as a mentor, helped support dental practitioners to comply with regulations and assisted them with complaints. The role has changed dramatically since 2006. It's now very much about advising NHS England about commissioning and contracting. As dental advisor you are now part of the contracting team, providing clinical advice to assist them in understanding the rationale behind the numbers that they come up with. It's less of a face-to-face, intermediary role with dentists because the CQC are doing that now. For some people it's for the better and others feel it's not what they signed up for as they wanted to be more on the dentists' side than on the contracting side.

\section{You have written books and articles on medico-legal matters - what drew you to this?}

That came about because I was recruited by Dental Protection. They were looking for someone young to be one of their advisors and I was very active at the time with the BDA. I was the youngest dental advisor there and I felt somewhat of a fraud. So to justify my existence I did a masters in law and then I told Trevor Burke from Dental Update that I was happy to write a few articles on the legal aspects of dentistry. He said, 'once you can write two articles, why don't you write three, and if you are writing three, why not write the book!'

\section{Do you feel that dentists generally deal well with complaints?}

If I was ever going to do a $\mathrm{PhD}$ it would be on the effect complaints have on dentists and dental teams. We focus our entire perspective on the complaint and sorting the patient out, and we almost forget the recipient of the complaint. A complaint can have a huge impact on dentists as professionals, they take it personally. As a dentist you are not part of a faceless organisation, it's you that is at the end of it. It's quite debilitating when you have a complaint against you. One of the issues is around professional competence and confidence. When a complaint is made you lose focus, and you start to lose confidence and question everything you do. If there is no support network around you (whether from a dental organisation or your family) you basically collapse.

\section{What are your views on direct access for DCPs?}

Direct access is a good idea because it allows DCPs who are highly trained to do something on their own. They have the necessary skill-set to do diagnosis because they can pick up a probe and do pocket charts, bleeding indices etc, and diagnosis is part of that. It's a great opportunity but it's not for everybody.

In our own practice we have completely polarised views. We have a hygienist who has been qualified for over 20 years who 
says, 'I don't want to do anything without prescription, this is a terrible thing to do. We can't have this.' Then we have someone qualified only three years who says, 'Fantastic. Bring it on, I'm happy to have the increased responsibility.'

From a Dental Protection perspective we have issued a position statement and our view is that we are not changing our indemnity structure at the moment because we don't know the risks. In the end it depends on what the DCPs and patients actually do. If the patients end up saying that they are not very interested and want to see the dentists first or if hygienists decide they don't want the responsibility, then there will be no change in the risk.

Direct access fits in perfectly with the new contract in terms of team working and care pathways. I think people are probably upset because of the way it was introduced by the GDC at very short notice. I'm sure once people get their head around that, it will be accepted.

\section{Postgraduate education: why is it so important?}

You just have to make a commitment to never stop learning. I'm running a postgraduate certificate in dental law and ethics at the University of Bedfordshire at the moment, which is now in its second cohort, and reading my student's essays I get a completely different perspective on something I thought I already knew about. This will often actually influence the way I advise Dental Protection members because I'll think 'that's an interesting way of looking at it'. So whether you are teaching it or studying it you will never stop learning as long as you are open to new ideas.

\section{Why are people often resistant to CPD?}

The resistance might be because they feel that they are forced to do it. I sense that more from DCPs, because they feel like they have to pay for their jobs. Once people are at the course, they usually feel they benefit from it. My biggest concern about CPD is that so much of it can be done online, so you never get the benefit of conferences - talking to other people, listening to other people - which is very isolating. I think the other problem is that there is almost too much choice now, so it could possibly be choice fatigue.

\section{If you had the power to make three subjects compulsory as part of postgraduate dental education what would they be?}

- Communication skills such as body language and basic psychology. This is something that we were never really taught as undergraduates but it has become so much a part of dentistry. Most of the time it is intuitive and you know what is going on in terms of the practice and how things operate as regard to stress, anxiety and management. But I think having some formal basis to it helps you to be more attune to it.

- I think the other thing, for practice owners, is probably practice management. Even now if you look around at postgraduate education not much is delivered at that level on this topic. For most practice owners the business does well in spite of us. If something went wrong you might not know exactly what went wrong or how to improve it. There are a number of consultants out there who do a good job and actually getting that information to people would be helpful.

- The last one would be changing behaviour; the preventive approach. I'm not sure we entirely know how to change people's behaviour, whether it's smoking, gum disease, alcohol reduction or attending regular checkups. There is more to it than just saying 'please do it'.

I think those sorts of subjects are important particularly as postgraduate dentists because the undergraduate courses are so packed they don't need any more! Once you are out there in practice you really see the value of those particular skills.

\section{What are your top 5 tips to dentists who are thinking about setting up their own practice?}

1. Get the best advice. There are a whole load of organisations out there that provide this. Start from the premise that you don't know much about it.

2. Understand the market. The market has changed dramatically over the years that I have been a practice owner. I think you need to be very aware of where the marketplace is.

3. Do it because you want to do it and not because your friends or peers are doing it. Because it is a hard job to do and you have to want to do it yourself.

4. Be aware that it isn't everyone's cup of tea. It is sometimes an isolated job and you feel like that the whole world is fighting against you. There's nothing wrong with working for somebody else. You can have a successful and very happy life doing that. Running a practice involves a different skill set. I know plenty of my friends perhaps regret doing it.

5. Plan your exit. You need to know where you are going with it - is it short-term or long-term. Don't just stumble into it.

\section{What are you most proud of?}

I'm proud of the practice. I'm proud of working for a leading organisation like Dental Protection Ltd (DPL). And cheesy as it might sound, I'm really proud of my wife and family. My wife looks after our four kids, helps to run the practice and is a dentist as well. All credit to her to allow me to do the things I'm doing because if she wasn't there I wouldn't be able to do half those things. I'm proud and grateful for that.

\section{What do you do in your spare time?}

Photography. Particularly, black and white photography. I started an Open College of Arts distance-learning degree last year. I love cooking too. I cook to relax.

\section{What does your working week look like? How do you fit all this in?}

I do something different each day. So Monday is practice, Tuesday is DPL, Wednesday is DPL Practice, Thursday is PCT, Friday is a half-day with time for gym and cooking. The jobs are all potentially full-time jobs so it involves balancing everything. So some simple things help. For example when marking postgraduate certificate essays, I can do one on my way on the train from Woodford to Oxford Circus (to go to Dental Protection) and one on the way back. Managing your time is very important and you certainly need good support at home.

Interview by Ruth Doherty 